\title{
Relationship between Damage Rate of High-Voltage Electrical Equipment and Instrumental Seismic Intensity
}

\author{
Rushan Liu (D, Mingpan Xiong, and Deyuan Tian (D) \\ Key Laboratory of Earthquake Engineering and Engineering Vibration, Institute of Engineering Mechanics, \\ China Earthquake Administration, Harbin 150080, China \\ Correspondence should be addressed to Rushan Liu; liurushan@sina.com and Deyuan Tian; 1981138215@qq.com
}

Received 22 February 2020; Revised 24 November 2020; Accepted 30 December 2020; Published 9 January 2021

Academic Editor: Fabrizio Paolacci

Copyright (c) 2021 Rushan Liu et al. This is an open access article distributed under the Creative Commons Attribution License, which permits unrestricted use, distribution, and reproduction in any medium, provided the original work is properly cited.

Based on the actual damage data of high-voltage electrical equipment in electric substations in the Wenchuan earthquake, this paper uses the cumulative Gaussian distribution function to describe the relationship between the damage rate of high-voltage electrical equipment and the instrumental seismic intensity. The instrumental seismic intensity at strong motion observation stations in the Wenchuan earthquake is calculated, and the Kriging interpolation method is used to estimate the instrumental seismic intensity at $110 \mathrm{kV}$ and above voltage level substations in Mianyang, Deyang, Guangyuan, and Chengdu of Sichuan Province. A cumulative Gaussian distribution function is then used to fit the damage rate-instrumental seismic intensity relationship curve for six types of high-voltage electrical equipment such as the transformer, circuit breaker, voltage mutual inductor, current mutual inductor, isolating switch, and lightning arrester. The results show that transformers have the highest vulnerability during earthquakes, and they suffered a certain level of damage even under low instrumental intensity. The second most vulnerable equipment is the circuit breaker, followed by the lightning arrester, transformer, and isolating switch, which share a similar vulnerability curve.

\section{Introduction}

Numerous earthquakes at home and abroad have caused serious damage to high-voltage electrical equipment in the transformer substations which resulted in the failure of power grid function in the affected areas and caused great difficulties for postevent emergency rescue efforts, the lives of the affected people, and the resettlement efforts after the disaster. Research on the vulnerability of high-voltage electrical equipment in the transformer substations is of great significance for improving the seismic performance of electrical equipment, assessing the damage and functional failure of power facilities and speeding up emergency repair efforts after an earthquake.

The research activities on the seismic vulnerability of high-voltage electrical equipment can be divided into three main categories: theoretical and numerical simulation, shaking table test, and statistical analysis [1]. The first two are mainly used for studying the seismic capability of the equipment, simulating seismic response and damage mechanism, and developing techniques for earthquake resistance and damage mitigation such as seismic base isolation [2-4].

The statistical method is used for studying the damage rates of the equipment under different ground motion intensities based on the samples of high-voltage electrical equipment damaged in earthquakes so as to obtain the vulnerability of the equipment. This method is an empirical approach that is directly linked to the actual seismic damage and is often used for seismic risk analysis, damage estimation, and economic loss assessment of the electric equipment.

In the 1990s, the Pacific Earthquake Engineering Center (PEER) and Pacific Gas and Electric Company in the US jointly established the Database of Seismic Performance of Transformer Substation Equipment for California, which recorded the damage to electrical equipment of 60 substations for different voltage classes with $220 \mathrm{kV}$ and above in 12 earthquakes in California. The vulnerability curves of high-voltage electrical equipment were statistically calculated, and the results were 
widely used in postdisaster assessment for electrical power system [5]. The Applied Technology Council (ATC) in the US provided seismic vulnerability curves for various lifelines, which were used in the seismic risk analysis system by Federal Emergency Management Agency (FEMA) [6, 7].

In recent years, a few scholars in China have studied the seismic vulnerability of substation electrical equipment with oil-immersed high-voltage transformer connected to the pipe busbar $[8,9]$; He et al. provided seismic vulnerability curves of transformers, busbars, and power transmission towers based on seismic damage data [10]; Liu et al. used the Weibull distribution function to fit the seismic vulnerability curves of electric porcelain electrical equipment [11]; Yang studied the relationships between the damage probability of various high-voltage electrical equipment with the peak ground acceleration and acceleration response spectrum and analyzed the functional failure modes of transformer substations under different peak ground accelerations [12].

Substantial progress has been made recently in constructing the rapid seismic intensity reporting system in various regions of China [13], and the system can quickly produce spatial distribution information on instrumental seismic intensity after an earthquake. Rapid assessment of seismic disaster based on instrumental seismic intensity meets the urgent need for postearthquake emergency response and rescue as well as engineering repair efforts. The research on the vulnerability of high-voltage electrical equipment based on instrumental seismic intensity is the basis of rapid seismic disaster assessment of power facilities.

However, the previous studies on the vulnerability of electrical equipment were based on peak acceleration, acceleration response spectrum, or traditional intensity. There were few published reports on studying the vulnerability of substation high-voltage electrical equipment based on instrumental seismic intensity.

To study the vulnerability of substation high-voltage electric equipment, this paper first calculated the instrumental intensities at strong motion observation stations in Wenchuan earthquake. The Kriging interpolation method was used to calculate the instrumental seismic intensities at a total of $121110 \mathrm{kV}$ and above substations for the national power grid in the worst-hit areas of Mianyang, Deyang, Guangyuan, and Chengdu in Wenchuan earthquake. Based on the seismic damage data of high-voltage electrical equipment, a cumulative Gaussian distribution function was used to express the relationship between damage rate and instrumental seismic intensity of high-voltage electrical equipment such as the transformer, circuit breaker, voltage mutual inductor, current mutual inductor, isolating switch, and lightning arrester, which was then used as the basis for seismic risk assessment and emergency response of power facilities.

\section{Instrumental Seismic Intensity at Strong Motion Observation Stations}

The instrumental seismic intensity is the intensity calculated using the strong motion observation records according to a specified method, and it directly reflects the ground motion intensity at the observation site and can be quickly obtained after an earthquake [14]. Rapid seismic intensity reporting systems have been constructed, and different algorithms for instrumental seismic intensity have been implemented in countries and regions such as the United States, Japan, and Taiwan. The national rapid seismic intensity reporting and early warning project in China is well under construction with a few rapid seismic intensity reporting networks having already been completed in a few selected regions, and an interim regulation for the calculation of instrumental seismic intensity has also been promulgated.

In accordance with the interim regulation, the calculation method for instrumental seismic intensity is defined as follows: the baseline correction and band-pass filtering were carried out first for the three-component seismic acceleration or velocity records at the observation sites, and the three-component synthesis was performed according to equations (1) and (2) to obtain the peak ground acceleration (PGA) and peak ground velocity (PGV). PGA and PGV were then used in equation (3) and (4) to calculate $I_{\mathrm{PGA}}$ for the peak seismic acceleration and $I_{\mathrm{PGV}}$ for the peak seismic velocity. Instrumental seismic intensity $I$ is finally determined by equation (5). The instrumental seismic intensity is categorized into scales from I to XII.

$$
\begin{aligned}
& \mathrm{PGA}=\max \left[\sqrt{a\left(t_{i}\right)_{E-W}^{2}+a\left(t_{i}\right)_{N-S}^{2}+a\left(t_{i}\right)_{U-D}^{2}}\right], \\
& \mathrm{PGV}=\max \left[\sqrt{v\left(t_{i}\right)_{E-W}^{2}+v\left(t_{i}\right)_{N-S}^{2}+v\left(t_{i}\right)_{U-D}^{2}}\right] .
\end{aligned}
$$

In equation (1), $a\left(t_{i}\right)$ is the acceleration record in different directions at time $t_{i}$; in equation (2), $v\left(t_{i}\right)$ is the speed record in different directions at time $t_{i}$.

$$
I_{\mathrm{PGA}}= \begin{cases}3.17 \lg (\mathrm{PGA})+6.59, & \text { when the PGA was synthesized from three directions } \\ 3.20 \lg (\mathrm{PGA})+6.59, & \text { when the PGA was synthesized from two horizontal directions } \\ 3.23 \lg (\mathrm{PGA})+6.82, & \text { when the PGA was synthesized from a single direction }\end{cases}
$$




$$
\begin{aligned}
& I_{\mathrm{PGV}}=\left\{\begin{array}{l}
3.00 \lg (\mathrm{PGV})+9.77, \quad \text { when the PGA was synthesized from three directions, } \\
2.96 \lg (\mathrm{PGV})+9.78, \quad \text { when the PGA was synthesized from two horizontal directions, } \\
3.11 \lg (\mathrm{PGV})+10.21, \quad \text { when the PGA was synthesized from a single direction, }
\end{array}\right. \\
& I=\left\{\begin{array}{l}
I_{\mathrm{PGV}}, \quad I_{\mathrm{PGA}} \geq 6.0 \text { and } I_{\mathrm{PGV}} \geq 6.0, \\
\frac{\left(I_{\mathrm{PGA}}+I_{\mathrm{PGV}}\right)}{2}, \quad I_{\mathrm{PGA}}<6.0 \text { or } I_{\mathrm{PGV}}<6.0, \\
1.0, \quad I \leq 1.0, \\
12.0, \quad I \geq 12.0 .
\end{array}\right.
\end{aligned}
$$

Based on the strong motion acceleration records at 255 strong earthquake stations in Sichuan, Gansu, Ningxia, and Shaanxi during the Wenchuan earthquake and according to the definition specified in equations (1)-(5), the data obtained at these strong motion observation stations were processed, and the instrumental seismic intensities at these locations were calculated. The comparison between the seismic intensity at strong motion observation stations and the instrumental seismic intensity at the same sites is shown in Figure 1.

From Figure 1, the following can be stated. (1) The mean instrumental intensity was in good agreement with the traditional intensity in regions of intensity VIII or below, while the instrumental intensity was lower than the traditional intensity in regions of intensity IX or above. (2) The instrumental intensity had some dispersion from the traditional intensity, and the dispersion was relatively large in low-intensity regions. As the intensity increased, the dispersion decreased. There were more data points in regions of intensity between V and VII, the maximum difference between the instrumental intensity and traditional intensity was close to 2 , and the dispersion in intensity VIII regions was relatively small.

\section{Interpolation of Instrumental Seismic Intensity at Substations}

The Kriging interpolation method was used to calculate the instrumental intensity at the substation based on the instrumental seismic intensity and geo-coordinates of the strong motion observation station. The Kriging interpolation method is an interpolation method named after South African geologist P. G. Krige by French scientist Matalon [15], which is widely used in contour line interpolation in many fields. This approach is based on the regionalized variable theory and the variogram theory, and the estimated values are obtained under the premise of ensuring that the estimated values satisfy the unbiased condition and the minimum variance condition. The
Kriging interpolation method considers not only the positional relationship between the points to be evaluated and the sample points but also the spatial correlation of all known points near the point to be evaluated, and thus it greatly reduces the systematic error in instrumental intensity estimation.

It is assumed that $f(x)$ is the regionalized variable in the space where the interpolation point and the sample point are located, and it is intrinsic, and $f_{i}(i=1,2, \ldots, n)$ is the corresponding value at the sampling point $x_{i}(i=1,2, \ldots, n)$. The estimated value of $f_{0}$ is $f_{0}^{*}$, and $f_{0}^{*}$ meets the following condition:

$$
f_{0}^{*}=\sum_{i=1}^{n} \lambda_{i} f_{i} \quad, i=1,2, \ldots, n .
$$

The coefficient $\lambda_{i}(i=1,2, \ldots, n)$ could be calculated according to the principle of unbiasedness and minimum variance of error.

According to the principle of unbiasedness, there is

$$
E\left[f_{0}^{*}-f_{0}\right]=0 .
$$

Thus, the following can be concluded:

$$
\sum_{i=1}^{n} \lambda_{i}=1
$$

The error variance is

$$
\begin{aligned}
S_{E}^{2} & =E\left[f_{0}^{*}-f_{0}\right]^{2}-\left\{E\left[f_{0}^{*}-f_{0}\right]\right\}^{2} \\
& =\sum_{i=1}^{n} \sum_{j=1}^{n} \lambda_{i} \lambda_{j} C_{i, j}-2 \sum_{i=1}^{n} \lambda_{i} C_{i, 0}+C_{0,0} .
\end{aligned}
$$

The partial derivative for the error variance can be calculated:

$$
\frac{\partial S_{E}^{2}}{\partial \lambda_{i}}=2 \sum_{j=1}^{n} \lambda_{j} C_{i, j}-2 C_{i, 0} .
$$




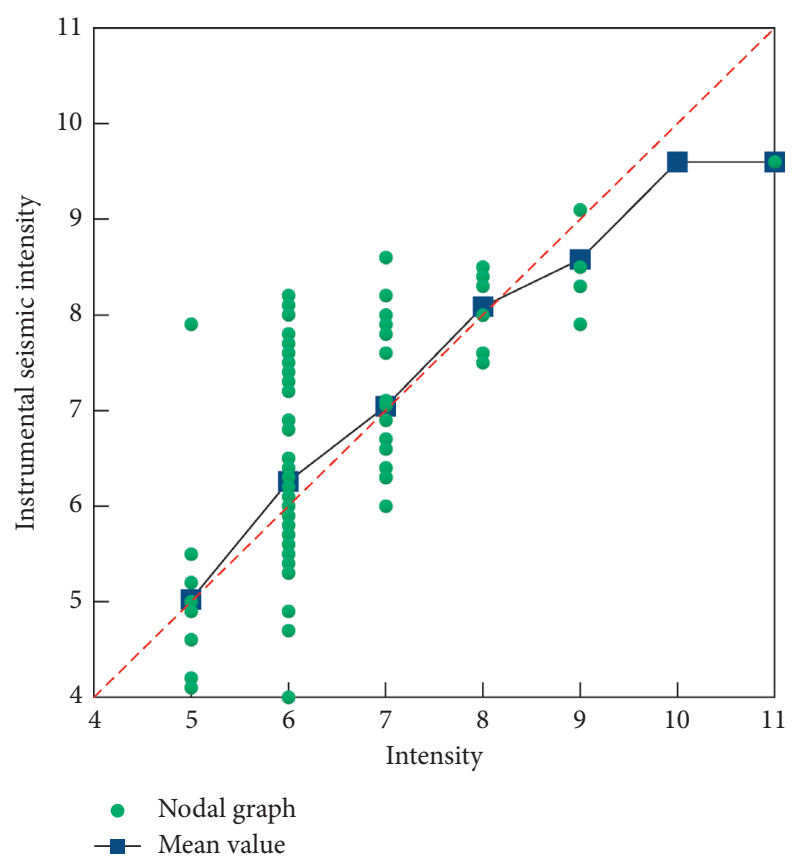

FIGURE 1: Comparison of seismic intensity and instrumental seismic intensity at strong motion observation stations.

To minimize the error variance, the extreme value of the error variance needs to be calculated, and the Lagrangian multiplier method is used. Assume

$$
F=S_{E}^{2}-2 t\left(\sum_{i=1}^{n} \lambda_{i}-1\right) .
$$

We can calculate the partial derivatives, respectively, for $\lambda_{i}$ and $t$, which are set to be equal to zero:

$$
\left\{\begin{array}{l}
\frac{\partial F}{\partial \lambda_{i}}=2 \sum_{j=1}^{n} \lambda_{j} C_{i, j}-2 C_{i, 0}-2 t=0 \\
\frac{\partial F}{\partial t}=-2\left(\sum_{i=1}^{n} \lambda_{i}-1\right)=0 .
\end{array}\right.
$$

Equation (12) can be arranged as follows:

$$
\left\{\begin{array}{l}
\sum_{j=1}^{n} \lambda_{j} C_{i, j}-t=C_{i, 0}, \\
\sum_{i=1}^{n} \lambda_{i}=1 .
\end{array}\right.
$$

$\lambda_{i}$ and $t$ can be solved from equation (13). When the regionalized variable does not satisfy the second-order stationary hypothesis but satisfies the intrinsic assumption, the variogram and covariance functions should have the following relationships:

$$
C(m)=C(0)-y(m) .
$$

Substituting equation (12) into equation (11), we should have the following:

$$
\left\{\begin{array}{l}
\sum_{j=1}^{n} \lambda_{j} y\left(x_{i}-x_{j}\right)+t=y_{i, 0}, \\
\sum_{i=1}^{n} \lambda_{i}=1
\end{array}\right.
$$

After $\lambda_{i}$ is calculated from equation (15), it can be brought into equation (6) to obtain the estimated value of $f_{0}^{*}$.

The power supply system in Sichuan Province is composed of state grid and power grids administered by local power companies, and state grid is the backbone. The Wenchuan earthquake caused severe damage to the power grid in Sichuan Province [16]. A total of 121 substations with voltage of $110 \mathrm{kV}$ and above in the state grids in Deyang, Mianyang, and Guangyuan and selected areas of Chengdu such as Dujiangyan, Pengzhou, Chongzhou, Wenjiang, and Pixian and those in Aba autonomous region managed by State Grid Company were selected as the statistical analysis samples for the study on vulnerability of high-voltage electrical equipment. According to the spatial distribution of the strong motion observation stations, the instrumental seismic intensities at the substations calculated by the above Kriging interpolation method are shown in Table 1.

\section{Statistical Method for Damage Rate of Various High-Voltage Electrical Equipment in Substations}

All high-voltage electrical instruments outside the substations such as circuit breakers, isolating switches, voltage mutual inductors, current mutual inductors, and lightning arresters belong to porcelain-column type structure. Their earthquake damage patterns were mainly cracks and oil 
TABLE 1: Substations of $110 \mathrm{kV}$ and above and instrumental seismic intensity.

\begin{tabular}{|c|c|c|c|c|c|c|c|}
\hline Region & $\begin{array}{c}\text { Transformer } \\
\text { substation }\end{array}$ & $\begin{array}{c}\text { Voltage } \\
\text { class }\end{array}$ & $\begin{array}{c}\text { Instrumental seismic } \\
\text { intensity }\end{array}$ & Region & $\begin{array}{c}\text { Transformer } \\
\text { substation }\end{array}$ & $\begin{array}{l}\text { Voltage } \\
\text { class }\end{array}$ & $\begin{array}{c}\text { Instrumental seismic } \\
\text { intensity }\end{array}$ \\
\hline Deyang & Tanjiawan station & 500 & 8.3 & Chengdu & Shuzhou station & 500 & 8.1 \\
\hline Deyang & Mengjia station & 220 & 8.5 & Chengdu & Danjing station & 500 & 7.7 \\
\hline Deyang & Wulidui station & 220 & 8.3 & Chengdu & Longxing station & 220 & 7.8 \\
\hline Deyang & Gucheng station & 220 & 8.1 & Chengdu & Huilong station & 220 & 8.7 \\
\hline Deyang & Wan'an station & 220 & 8.4 & Chengdu & Yufu station & 220 & 7.6 \\
\hline Deyang & Xinshi station & 220 & 8.6 & Chengdu & Juyuan station & 220 & 9.0 \\
\hline Deyang & Yunxi station & 220 & 8.8 & Chengdu & Datian station & 110 & 7.5 \\
\hline Deyang & Chengnan station & 110 & 8.4 & Chengdu & $\begin{array}{c}\text { Chongzhou } \\
\text { station }\end{array}$ & 110 & 7.9 \\
\hline Deyang & Deyang station & 110 & 8.2 & Chengdu & $\begin{array}{c}\text { Wangchang } \\
\text { station }\end{array}$ & 110 & 8.0 \\
\hline Deyang & Feng'guang station & 110 & 8.6 & Chengdu & Yongkang station & 110 & 7.8 \\
\hline Deyang & Jinghu station & 110 & 8.3 & Chengdu & $\begin{array}{c}\text { Guangming } \\
\text { station }\end{array}$ & 110 & 8.3 \\
\hline Deyang & Qingping station & 110 & 8.4 & Chengdu & Taiqing station & 110 & 8.2 \\
\hline Deyang & Tianyuan station & 110 & 8.4 & Chengdu & Tianpeng station & 110 & 8.4 \\
\hline Deyang & Yangjia station & 110 & 8.5 & Chengdu & Linwan station & 110 & 7.9 \\
\hline Deyang & $\begin{array}{l}\text { Binglinggong } \\
\text { station }\end{array}$ & 110 & 8.2 & Chengdu & Pixian station & 110 & 7.7 \\
\hline Deyang & Datang station & 110 & 8.1 & Chengdu & Gongping station & 110 & 7.6 \\
\hline Deyang & Gaoxin station & 110 & 8.4 & Chengdu & Haike station & 110 & 7.7 \\
\hline Deyang & Guanghan station & 110 & 8.6 & Chengdu & Liucheng station & 110 & 7.6 \\
\hline Deyang & Jinxing station & 110 & 8.3 & Chengdu & Guanxian station & 110 & 9.7 \\
\hline Deyang & Lianshan station & 110 & 8.2 & Chengdu & Jinjiang station & 110 & 9.2 \\
\hline Deyang & Luocheng station & 110 & 8.2 & Chengdu & Xujia station & 110 & 9.3 \\
\hline Deyang & Sanxing station & 110 & 8.2 & Mianyang & Gufeng station & 220 & 7.8 \\
\hline Deyang & Xiangyang station & 110 & 8.1 & Mianyang & Jiaqiao station & 220 & 7.6 \\
\hline Deyang & Xiaohan station & 110 & 8.3 & Mianyang & Yongxing station & 220 & 8.1 \\
\hline Deyang & Banzhu station & 110 & 8.4 & Mianyang & Dakang station & 220 & 9.1 \\
\hline Deyang & Yuying station & 110 & 8.3 & Mianyang & Tianming station & 220 & 8.4 \\
\hline Deyang & Minzhu station & 110 & 9.0 & Mianyang & Baisheng station & 220 & 8.0 \\
\hline Deyang & Yanshi station & 110 & 8.5 & Mianyang & Anxian station & 220 & 9.1 \\
\hline Deyang & Bajiao station & 110 & 9.4 & Mianyang & Sanyuan station & 110 & 7.5 \\
\hline Deyang & Xiaoquan station & 110 & 8.6 & Mianyang & Gaoshui station & 110 & 7.9 \\
\hline Deyang & Baimiao station & 110 & 8.4 & Mianyang & Mianyang station & 110 & 7.9 \\
\hline Deyang & Dongbei station & 110 & 8.7 & Mianyang & Nanta station & 110 & 7.8 \\
\hline Deyang & Longqiao station & 110 & 8.6 & Mianyang & Puming station & 110 & 7.9 \\
\hline Deyang & Mianzhu station & 110 & 8.7 & Mianyang & Santai station & 110 & 7.4 \\
\hline Deyang & Lianglukou station & 110 & 8.8 & Mianyang & Shiqiaopu station & 110 & 8.0 \\
\hline Deyang & $\begin{array}{c}\text { Shuangsheng } \\
\text { station }\end{array}$ & 110 & 8.7 & Mianyang & Tangxun station & 110 & 7.9 \\
\hline Deyang & Tutang station & 110 & 8.6 & Mianyang & Tieniu station & 110 & 8.1 \\
\hline Deyang & Wanchun station & 110 & 8.9 & Mianyang & Xinzao station & 110 & 8.0 \\
\hline Deyang & Yongning station & 110 & 8.5 & Mianyang & Yuanyi station & 110 & 8.1 \\
\hline Deyang & Xiangshan station & 110 & 9.0 & Mianyang & Hongren station & 110 & 7.7 \\
\hline Deyang & Hanwan station & 110 & 9.1 & Mianyang & Changqing station & 110 & 7.7 \\
\hline Deyang & $\begin{array}{l}\text { Chuanxindian } \\
\text { station }\end{array}$ & 110 & 9.1 & Mianyang & Weicheng station & 110 & 7.6 \\
\hline Guangyuan & Chihua station & 220 & 9.8 & Mianyang & $\begin{array}{l}\text { Xianrenqiao } \\
\text { station }\end{array}$ & 110 & 7.8 \\
\hline Guangyuan & Hongjiang station & 220 & 7.8 & Mianyang & Xiaojian & 110 & 7.8 \\
\hline Guangyuan & Baishiyan station & 220 & 9.7 & Mianyang & Youxian station & 110 & 7.9 \\
\hline Guangyuan & Yuanjiaba station & 220 & 10.0 & Mianyang & Xiaoting station & 110 & 8.2 \\
\hline Guangyuan & Lingjiang station & 110 & 8.0 & Mianyang & Huagai station & 110 & 8.1 \\
\hline Guangyuan & Lantupo station & 110 & 9.1 & Mianyang & Jiepai station & 110 & 8.0 \\
\hline Guangyuan & Chengjiao station & 110 & 9.0 & Mianyang & $\begin{array}{c}\text { Erlangmiao } \\
\text { station }\end{array}$ & 110 & 9.7 \\
\hline Guangyuan & Jiange station & 110 & 9.3 & Mianyang & Ganxi station & 110 & 8.5 \\
\hline Guangyuan & Saxiba station & 110 & 9.5 & Mianyang & Majiaoba station & 110 & 10.0 \\
\hline
\end{tabular}


TABle 1: Continued.

\begin{tabular}{|c|c|c|c|c|c|c|c|}
\hline Region & $\begin{array}{c}\text { Transformer } \\
\text { substation }\end{array}$ & $\begin{array}{c}\text { Voltage } \\
\text { class }\end{array}$ & $\begin{array}{c}\text { Instrumental seismic } \\
\text { intensity }\end{array}$ & Region & $\begin{array}{c}\text { Transformer } \\
\text { substation }\end{array}$ & $\begin{array}{c}\text { Voltage } \\
\text { class }\end{array}$ & $\begin{array}{c}\text { Instrumental seismic } \\
\text { intensity }\end{array}$ \\
\hline Guangyuan & Xiasi station & 110 & 9.0 & Mianyang & Sanhe station & 110 & 8.2 \\
\hline Guangyuan & Shangxi station & 110 & 8.6 & Mianyang & Shawo station & 110 & 8.4 \\
\hline Guangyuan & Songlinpo station & 110 & 8.1 & Mianyang & Taibai station & 110 & 8.3 \\
\hline Guangyuan & Chaotian station & 110 & 9.4 & Mianyang & Zhongba station & 110 & 8.5 \\
\hline Guangyuan & Zhuyuan station & 110 & 10.3 & Mianyang & Jushui station & 110 & 9.1 \\
\hline Guangyuan & Sandui station & 110 & 10.4 & Mianyang & Xiaoba station & 110 & 8.9 \\
\hline Guangyuan & Muyu station & 110 & 11.2 & Mianyang & Yongan station & 110 & 9.4 \\
\hline Guangyuan & $\begin{array}{c}\text { Qiaozhuang } \\
\text { station }\end{array}$ & 110 & 11.1 & Mianyang & $\begin{array}{l}\text { Yuanmenba } \\
\text { station }\end{array}$ & 110 & 9.2 \\
\hline Aba station & Maoxian station & 500 & 8.0 & Mianyang & Leigu station & 110 & 10.0 \\
\hline Aba station & Yinxing station & 220 & 10.5 & & & & \\
\hline
\end{tabular}

leakage occurring in porcelain components or direct fracture of porcelain columns. The damage of the porcelain-column type structure equipment caused the aforementioned high-voltage electrical equipment to lose its normal use function. Most of the damage patterns of transformers in earthquakes were also the damage of porcelain-column type structure. The damage of the porcelain casing caused the transformer to lose its normal function. Although there was damage to oil pillow, radiator, wheel-rail fixing device, and transformer overturning at high intensity, there was no damage to the main structure of the transformer to cause its loss of normal use function.

Once the porcelain column structures were destroyed, the equipment with them could not be repaired but had to be completely replaced. At present, it is impossible to judge the damage degree of the porcelain-column-type structural equipment before the cracks, breaks, and other obvious damage phenomena. Therefore, according to whether the high-voltage electrical equipment could maintain its normal use function, the damage pattern for the equipment could be divided into two stages: damaged and intact, and there was no need to further divide damage pattern into five damage stages as used for building structures. Subsequently, for porcelain column structures like circuit breakers, isolating switches, voltage mutual inductors, current mutual inductors, and lightning arresters, crack appearance itself could be defined as in the damage stage; for transformers, the damage to the porcelain casing, oil leaking, or radiator malfunction would be defined as in the damage stage.

A substation usually has 1 to 3 working transformers and many sets for other types of high-voltage electrical equipment. The damage rate $R$ of a certain type of high-voltage electrical equipment in a substation can be expressed as follows:

$$
R=\frac{n}{N}
$$

where $n$ is the number of equipment damaged in the substation and $N$ is the total number of such equipment in the substation. The range of damage rate $R$ is $[0,1]$.

If the damage rate obtained for a type of high-voltage electrical equipment in each substation was considered as one sample, the least square fitting could be performed for all substation samples in Table 1 to obtain the functional expression of the relationship between the damage rate and instrumental seismic intensity for all types of high-voltage electrical equipment, which became the vulnerability curves of the equipment based on instrumental seismic intensity.

There were studies on the relationships of the damage probability of the transformers and the busbars with the peak ground motion which used a logarithmic cumulative Gaussian distribution function to fit the relationship curves [9]. In addition, there were other studies on the seismic vulnerabilities of basic components and structures of reinforced concrete which found that the use of a logarithmic cumulative Gaussian distribution function to express the relationship between their damage and the ground motion peak acceleration had a better rationality $[17,18]$. The instrumental seismic intensity had a linear relationship to some extent with the logarithms of the peak acceleration and the peak velocity. From the relationship between Gaussian distribution and logarithmic Gaussian distribution, it can be seen that the relationship between the damage rate of highvoltage electrical equipment and the instrumental seismic intensity could be fitted using the cumulative Gaussian distribution function.

If a random variable $x$ follows Gaussian distribution with an expected value of $\mu$ and a standard deviation of $\sigma$, the probability density function is

$$
f(x)=\frac{1}{\sigma \sqrt{2 \pi}} \exp \left[-\frac{(x-\mu)^{2}}{2 \sigma^{2}}\right] .
$$

The cumulative Gaussian distribution function is

$$
F(x)=0.5+0.5 \operatorname{erf}\left(\frac{x-\mu}{\sigma \sqrt{2}}\right),
$$

wherein the $\operatorname{erf}(x)$ function is

$$
\operatorname{erf}(x)=\frac{2}{\sqrt{\pi}} \int_{0}^{x} e^{-t^{2}} d t
$$

The average damage rate of various high-voltage electrical equipment in the substation and instrumental seismic intensity were fitted by formula (18) using the least squares method, and the damage rate curves of various 
types of high-voltage electrical equipment under different instrumental seismic intensities could be obtained.

\section{Results of Vulnerability Curve Fitting for Various Types of High-Voltage Electrical Equipment}

Using the substations listed in Table 1 as the samples, the damage rate-instrumental seismic intensity relationship could be fitted for transformer, circuit breaker, isolating switch, current mutual inductor, voltage mutual inductor, and lightning arrester to derive parameter values $\mu$ and $\sigma$ of cumulative Gaussian distribution function curves for these 6 types of high-voltage electrical equipment, as shown in Table 2.

The fitting goodness index RNew was used to represent the fitting goodness of the relationship between the damage rate of high-voltage electrical equipment and the instrumental seismic intensity. The formula for RNew is

$$
\mathrm{RNew}=\frac{\sum\left(y-y^{*}\right)^{2}}{\sum y^{2}},
$$

where $y$ is the actual observed value and $y^{*}$ is the predicted value by the fitted function.

According to equation (20), the fitting goodness of the relationship curve between the damage rate of various highvoltage electrical equipment and the instrumental intensity is shown in Table 3:

The curve fitting goodness of the relationship between transformer damage rate and instrumental seismic intensity is 0.809 , that of circuit breaker and voltage mutual inductor is about 0.7, and the curve fitting goodness of arrester, isolating switch, and current mutual transformer is about 0.6. It can be concluded that the fitted result could basically reflect the relationship between the instrumental seismic intensity and the damage rate of various types of high-voltage electrical equipment.

The fitted damage rate curves and original data samples of various high-voltage electrical equipment are shown in Figures 2(a)-2(f). It can be seen from Figure 2 that (1) for transformers, the damage rate was close to $20 \%$ when the instrumental intensity was VII, about $40 \%$ when the instrumental intensity was VIII, above $80 \%$ when the instrumental intensity was IX, and close to $100 \%$ when the instrumental intensity was X; (2) although damage occurred in other types of equipment other than the transformers when the instrumental seismic intensity was VII, the damage rate was very low, not exceeding $5 \%$, and the damage rate was below $15 \%$ when the instrumental intensity was VIII; when the instrumental seismic intensity was IX, the damage rate was about $40 \%$; the damage rate of circuit breakers reached $80 \%$, and the damage rates of transformers, isolating switches, and lightning arresters basically ranged between $45 \%$ and $60 \%$ when the instrumental seismic intensity was $\mathrm{X}$; (3) the dispersion of damage rates for various types of high-voltage electrical equipment in substations was still large under different instrumental seismic intensities; for example, the damage
TABLE 2: Gaussian distribution accumulation function curve parameter values of high-voltage electrical equipment damage rate.

\begin{tabular}{lcc}
\hline Equipment type & $\mu$ & $\sigma$ \\
\hline Transformer & 8.21 & 1.14 \\
Circuit breaker & 9.26 & 0.88 \\
Isolating switch & 10.03 & 1.48 \\
Lightning arrester & 9.68 & 1.26 \\
Current mutual inductor & 9.92 & 1.36 \\
Voltage mutual inductor & 9.67 & 1.22 \\
\hline
\end{tabular}

TABLE 3: The fitting goodness of the relationship curve between the damage rate of high-voltage electrical equipment and the instrumental seismic intensity.

\begin{tabular}{lc}
\hline Equipment type & Goodness of fitting (RNew) \\
\hline Transformer & 0.809 \\
Circuit breaker & 0.733 \\
Isolating switch & 0.617 \\
Lightning arrester & 0.610 \\
Current mutual inductor & 0.597 \\
Voltage mutual inductor & 0.680 \\
\hline
\end{tabular}

rate for transformer in some substations had reached $100 \%$ within the instrumental intensity range of VI-VII, while no damage occurred in other substations. From the fitted curve, the damage rate of transformers was less than $30 \%$; (4) since the maximum number of transformers in a substation did not exceed 3 , the damage rate values were only concentrated in several limited fixed values under various intensities; while there were usually more sets for other types of equipment in a substation, there were more sample points shown in the Figures 2(b)-2(f) for these types of equipment.

The damage rates and probability density distribution curves for various types of equipment were compared, respectively, as shown in Figures 3 and 4.

It could be seen from the comparison diagram in Figure 3 that the transformer was the most vulnerable to earthquake than other types of high-voltage electrical equipment, and its vulnerability was significantly higher than those for other types of equipment; the circuit breaker was the second most vulnerable in other types of equipment, and the damage rate curves of lightning arresters, mutual inductors, and isolating switches were close to each other.

It could be seen from Figure 4 that the probability density of damage rate of transformers reached a peak value when the instrumental seismic intensity was VIII, and the number of damaged transformers increased rapidly. The probability density of damage rate of circuit breakers reached a peak value when the instrumental intensity was IX, and the number of damaged circuit breakers increased the most; the probability density of damage rates of isolating switch, lightning arrester, current mutual inductor, and voltage mutual inductor reached peak values when their instrumental intensities were $\mathrm{X}$, and the number of damaged sets for these types of equipment increased rapidly. Figure 4 illustrates that on the one hand, different types of equipment had their respective damage-resistant strengths as the 


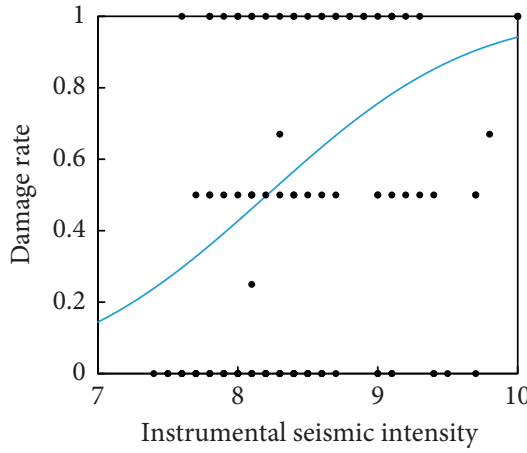

- Fitting curve

- Samples

(a)

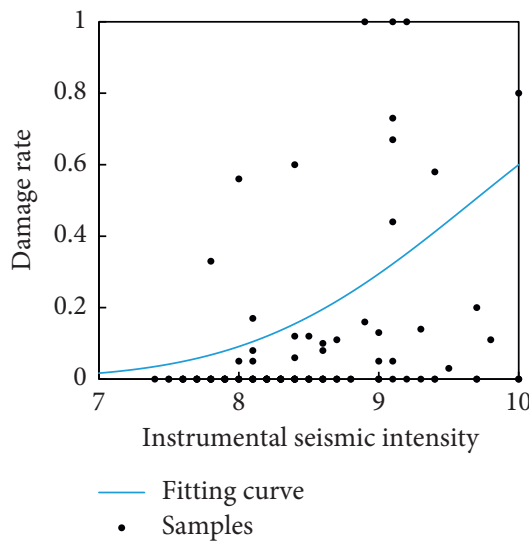

(d)

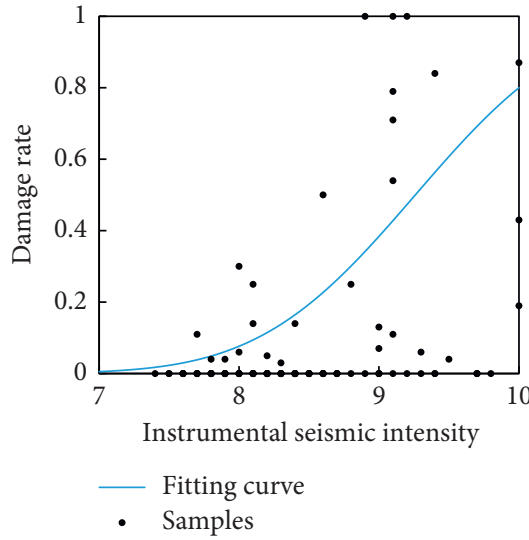

(b)

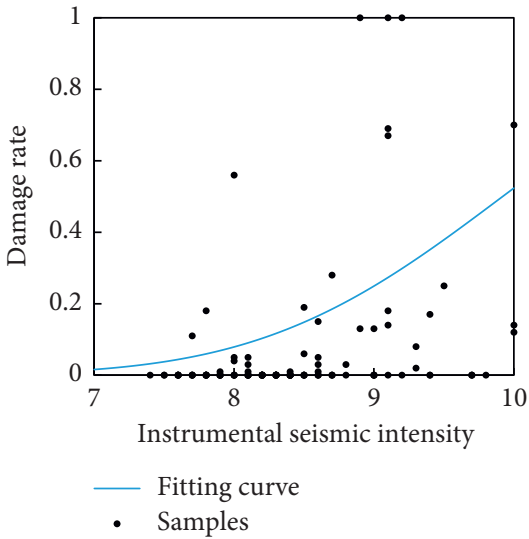

(e)

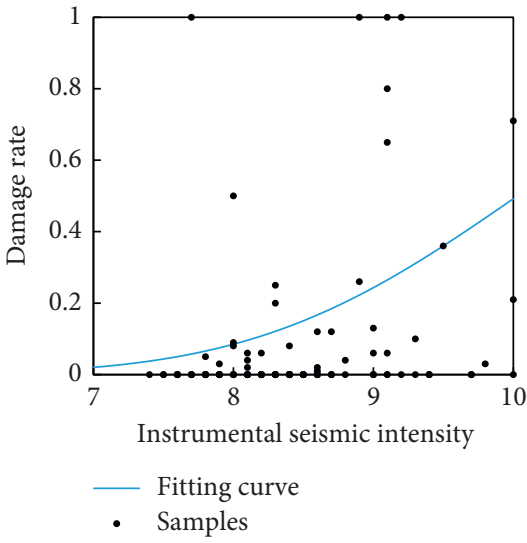

(c)

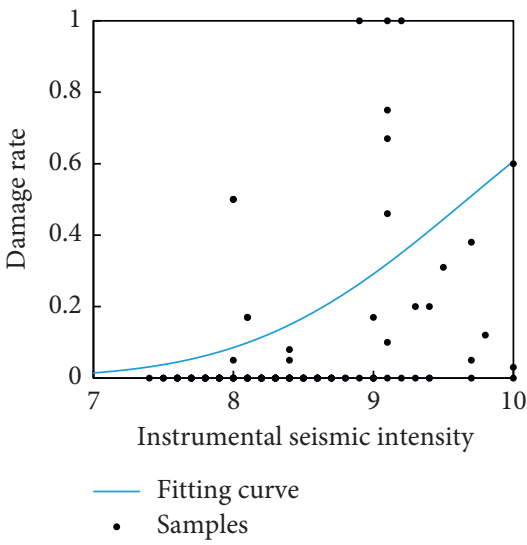

(f)

FIgURE 2: Damage rate fitted curves and samples distribution of high-voltage electrical equipment. (a) Transformer. (b) Circuit breaker. (c) Isolating switch. (d) Lightning arrester. (e) Current mutual inductor. (f) Voltage mutual inductor.

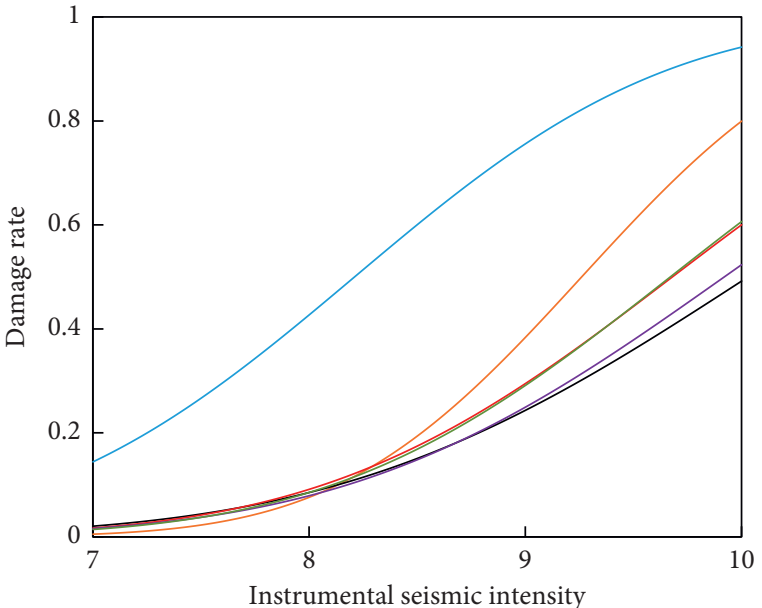
- Transformer
Isolating switch
Current mutual inductor

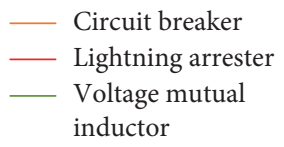

FIGURE 3: Damage probability curves for all kinds of high-voltage electrical equipment.

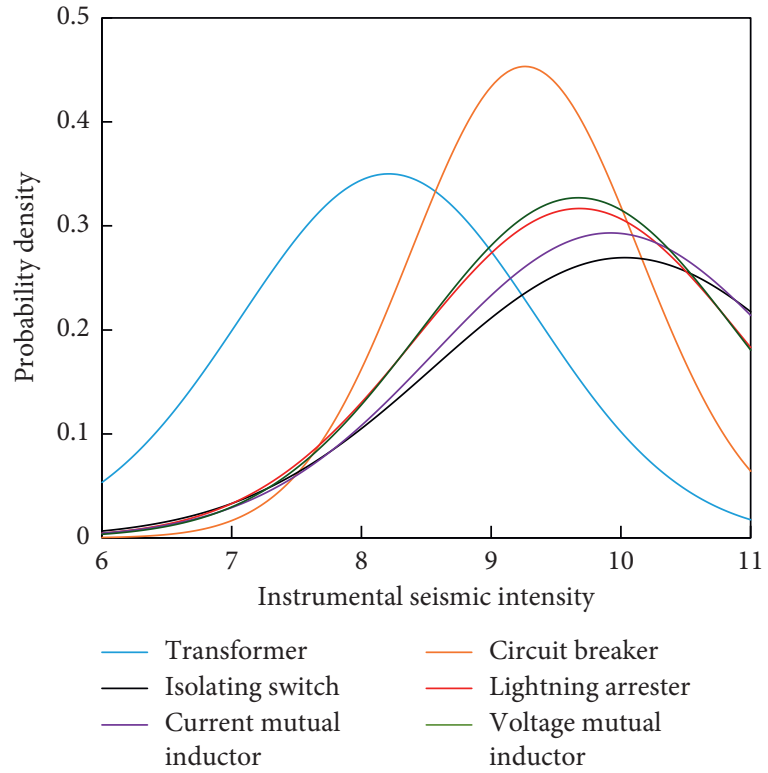

FIgURe 4: Probability density curves of damage rate for all kinds of high-voltage electrical equipment. 
ground motion intensity increased; on the other hand, the damage of each type of equipment around this intensity value was disperse under the influences of various incidental factors.

\section{Conclusion}

According to the strong motion acceleration records of Wenchuan earthquake, the Kriging interpolation method is used to calculate the instrumental seismic intensities at locations of a total of $121110 \mathrm{kV}$ and above substations in affected areas of Mianyang, Deyang, Guangyuan, and Chengdu in Wenchuan earthquake. The Gaussian distribution cumulative function is used to fit damage rate-instrumental seismic intensity relationship curve for transformer, circuit breaker, voltage mutual inductor, current mutual inductor, isolating switch, and lightning arrester to form vulnerability curves of high-voltage electrical equipment outside the substations based on the instrumental seismic intensity. The fitting results show that the transformers have the highest seismic vulnerability and endure certain levels of damage rate even under low instrumental intensity. The second most vulnerable equipment is the circuit breaker, followed by the lightning arrester, transformer, and isolating switch, and the seismic vulnerability curves for these types of equipment are relatively similar. The fragile link in the substations is mainly the transformer, which becomes the most important factor for the substations to maintain their functions in the earthquakes. It is necessary to speed up the research activities to improve the seismic capacity of the transformer through enhancing its shock absorption and seismic isolation performance.

At present, construction of a rapid seismic intensity reporting system is being vigorously promoted and developed in China, and a rapid reporting network has been formed in some provinces and regions, which can be used to timely disseminate the reporting information of the intensity after an earthquake. Instrumental seismic intensity will be widely used in earthquake emergency response efforts and disaster assessment. The vulnerability curve for high-voltage electrical equipment can be used for rapid assessment of seismic damage and economic loss of power equipment and can also provide reference for equipment emergency repair in power industry after an earthquake.

Wenchuan earthquake had a wide impact and heavy seismic damage. Many seismic damage samples have been obtained in regions with different levels of intensity, which provided a wealth of basic information for the study of the vulnerability of high-voltage electrical equipment. Due to sparse distribution of strong earthquake observation stations during Wenchuan earthquake, the instrumental seismic intensity values in locations of substations cannot be directly obtained. However, the instrumental seismic intensity values of substations estimated by the interpolation method must have certain errors compared with the actual values, which will bring some errors to the vulnerability statistics of highvoltage electrical equipment based on instrumental intensity. At the same time, the fitting of vulnerability curves needs to be further enriched by accumulating more seismic samples in the future, especially the samples in high-intensity regions of intensities $\mathrm{X}$ and $\mathrm{XI}$ need to be further enriched.

\section{Data Availability}

The data used to support the findings of this study are available from the corresponding author upon request.

\section{Conflicts of Interest}

The authors declare that they have no conflicts of interest regarding the publication of this paper.

\section{Acknowledgments}

This study was supported by the Special Fund for Basic Scientific Research Expenses of Institute of Engineering Mechanics (2018A02) and National Key R\&D Program of China (no. 2018YFC1504602).

\section{References}

[1] B. Wen, D. Niu, and P. Zhao, "An overview on aseismic reliability research in electric power system," Journal of Catastrophology, vol. 22, no. 4, pp. 86-90, 2007, (in Chinese).

[2] B. Wen, J. Dai, and Y. Yang, "Effectiveness study of combined control strategy based on base isolation and tuned mass damper on porcelain cylindrical equipment," Proceedings of The Chinese Society for Electrical Engineering, vol. 39, no. 13, pp. 3939-3946, 2019, (in Chinese).

[3] M. A. Saadeghvaziri, A. Ashrafi, N. H. Allaverdi et al., "Seismic response and rehabilitation of critical substation equipment," in Proceedings of 13th World Conference on Earthquake Engineering, IAEE, Vancouver, B. C., Canada, August 2004.

[4] Q. Xie and R.-y. Zhu, "Research state and development of seismic performance of large transformer," Transformer, vol. 48, no. 1, pp. 25-31, 2011, (in Chinese).

[5] T. Anagnos, Development of an Electrical Substation Equipment Performance Database for Evaluation of Equipment Fragilities, Pacific Earthquake Engineering Research Center, Davis Hall, UW. UC Berkeley, 1999.

[6] ATC, ATC 13 Earthquake Damage Evaluation Data for California, Advanced Technology Council, Redwood, CF, USA, 1985.

[7] FEMA\&NIBS, Earthquake Loss Estimation Methodology-HAZUS 1999, Federal EmergencyManagement Agency and National Institute of Building Science, Washington, DC, USA, 1999.

[8] M. E. M. G. Minjie, L. Chen, and Z. Ye, "Modeling and seismic fragility analysis of transformers," World Earthquake Engineering, vol. 23, no. 3, pp. 163-167, 2007, (in Chinese).

[9] Y. Hu and Q. Xie, "Seismic Vulnerability of substation equipment interconnected by rigid bus," Electric Power Construction, vol. 31, no. 7, pp. 22-28, 2010, (in Chinese).

[10] H. He, J. Guo, and Q. Xie, "Vulnerability analysis of power equipment caused by earthquake disaster," Power System Technology, vol. 35, no. 4, pp. 25-28, 2011, (in Chinese).

[11] Z. Liu, Z. Dai, and Z. Lu, "Weibull distribution based seismic vulnerability analysis of porcelain equipment," Power System Technology, vol. 38, no. 4, pp. 1076-1081, 2014, (in Chinese). 
[12] C. Yang, Vulnerability Analysis of High Voltage Electrical Equipment Based on Ground Motion Parameters, Institute of Engineering Mechanics, CEA, Harbin, China, (in Chinese), 2011.

[13] X. Wang, H.-m. Zhang, and Q. An, "Basic station selection and instrument analysis of inner mongolia seismic intensity rapid reporting and early warning project," Journal of Disaster Prevention and Reduction, vol. 34, no. 1, pp. 20-25, 2018, (in Chinese).

[14] X. Jin, H. Zhang, L. I. Jun et al., "Preliminary study on instrumental seismic intensity standard," Progress in Geophysics, vol. 28, no. 5, pp. 2336-2351, 2013, (in Chinese).

[15] G. Yang, G. Zhang, and S. Li, "Application of universal Kriging interpolation in geomagnetic map," Journal of ChineseI Nertial Technology, vol. 16, no. 2, pp. 162-166, 2008, (in Chinese).

[16] Sichuan Electric Power Experiment Research Institute, Wenchuan Earthquake Sichuan Power Grid Electrical Equipment Damage Report, Sichuan Electric Power Experiment Research Institute, Chengdu, (in Chinese), 2008.

[17] H. Hwang and J. Liu, "Seismic fragility analysis of reinforced concrete bridges," China Civil Engineering Journal, vol. 37, no. 6, pp. 47-51, 2004, (in Chinese).

[18] Y. Liu, Research on Seismic Performance and Fragility for Steel-concrete composite structural systems, Tsinghua University, Beijing, China, (in Chinese), 2009. 